\title{
The effect of high altitude on endothelial and vascular dysfunction markers in preeclamptic patients
}

\author{
SO Bashir ${ }^{1}$, H Suekit $^{1}$, AO Elkarib ${ }^{1}$, MA Dafaalla ${ }^{1}$, MB Abd Elrouf ${ }^{4}$, \\ MD Morsy ${ }^{1,2}$, M Eskandar ${ }^{3}$

\begin{abstract}
${ }^{1}$ Department of Physiology, College of Medicine, King Khalid University, Abha, Saudi Arabia
${ }^{2}$ Department of Physiology, College of Medicine, Menoufiya University, Shebin El-Kom, Menoufiya, Egypt

${ }^{3}$ Department of Obstetrics and Gynecology, College of Medicine, King Khalid University, Abha, Saudi Arabia

${ }^{4}$ Department of Biochemistry, College of Medicine, King Khalid University, Abha, Saudi Arabia
\end{abstract}

Received: May 13, 2014

Accepted: July 31, 2015

\begin{abstract}
Placental hypoxia, a major component of the pathophysiology of preeclampsia, is associated with various maternal vascular and endothelial dysfunctions. The higher incidence of preeclampsia at high altitude remains incompletely explained. The aim of the present study was to investigate the effect of high altitude on some endothelial and vascular dysfunction markers in normal and preeclamptic pregnancies. Eighty pregnant women (Paras 2-4) were enrolled in this study, which included four groups (each $n=20$ ): normal pregnancies at low altitude (NL), normal pregnancies at high altitude $(\mathrm{NH})$, preeclamptic pregnancies at low altitude (PL), and preeclamptic pregnancies at high altitude $(\mathrm{PH})$. In normal pregnancies at high altitude serum ET-1, plasma TXA 2 , and serum TNF- $\alpha$ levels increased significantly with a significant reduction in plasma $\mathrm{PGI}_{2}(66.81 \pm 7.36,122.86 \pm 13.37,102.23 \pm 13.31$, $191.57 \pm 19.68$, respectively) compared with the NL group $(48.92 \pm 4.58,89.03 \pm 10.67,69.86 \pm 7.97,238.01 \pm$ 24.55 , respectively). In preeclampsia at low altitude serum ET-1, plasma TXA 2 , and serum TNF- $\alpha$ levels increased significantly with a significant reduction in plasma $\mathrm{PGI}_{2}(88.39 \pm 9.54,162.73 \pm 15.92,142.39 \pm 15.37,149.155 \pm$ 15.66, respectively) compared with both NL and NH groups. High altitude significantly augmented these changes in preeclamptic patients $(117.75 \pm 12.96,211.01 \pm 22.69,196.86 \pm 17.64,111.92 \pm 10.74)$ compared with PL, NH and NL groups. In conclusion hypoxia at high altitude aggravated the disturbances in the levels of ET-1, TXA $2, \mathrm{PGI}_{2}$ and TNF- $\alpha$ associated with preeclampsia. This may contribute to the higher risk of preeclampsia at high altitude.
\end{abstract}

Keywords: preeclampsia, high altitude, tumor necrosis factor alpha, endothelin, thromboxane A2, prostacyclin

Preeclampsia remains one of the leading causes of maternal and fetal morbidity. Recent research has revealed that placental insufficiency, resulting in hypoxia and ischemia, is a central causative pathway in the development of preeclampsia $(10,26)$. Despite thorough characterization of the preeclamptic syndrome and incrimination of a suite of contributing circulating factors $(6,15,32)$, the mechanisms underlying the pathogenesis remain nebulous. Theories about etiological factors in preeclampsia include the reduction in uteroplacental blood flow, circulating factors of placental origin, placental oxidative stress and increased maternal vascular reactivity (32). The initiating event in preeclampsia is postulated to be reduced utero-placental perfusion as a result of an abnormal cytotrophoblast invasion of spiral arterioles. Placental ischemia is thought to lead to widespread activation/dysfunction of the maternal vascular endothelium. This enhances the formation of vasoactive factors like endothelin (ET-1) (13) and thromboxane A2 (TXA $)(22)$, as well as it increases vascular

Corresponding author: Professor Mohamed Darwesh Morsy

Department of Physiology, College of Medicine, Menoufiya University, Shebin El-Kom, Menoufiya, Egypt

Phone: +966544495223; Fax: +96672418194; E-mail: Morsydarwesh@yahoo.com 
sensitivity to angiotensin II, and decreases the formation of vasodilators such as nitrous oxide (17) and prostacyclin $\left(\mathrm{PGI}_{2}\right)(13)$. Maternal endothelial cell activation/dysfunction enhances the synthesis of inflammatory cytokines such as tumor necrosis factor alpha (TNF- $\alpha$ ). TNF- $\alpha$ has been shown to induce structural and functional alterations of placental endothelial cells during trophoblast development in preeclampsia (35). These endothelial abnormalities, in turn, cause hypertension by impairing renal-pressure and increasing total peripheral resistance.

Studies indicate that the incidence of preeclampsia is increased by two- to fourfold at high altitude $(>2700 \mathrm{~m})(20,36)$. However, the link between maternal hypoxemia induced by residence at high altitude and the increased risk for preeclampsia is yet to be fully and satisfactorily explained despite a number of studies both at the morphological and molecular levels. Xiao et al. suggested that high altitude hypoxia altered uterine vessels myogenic activity via enhanced oxidative stress (34). Residence at high altitude per se was reported to induce significant elevation of several vasoconstriction relative to vasodilatation mediators $(3,18)$. This effect is apparently more pronounced during pregnancy, with greater levels of certain vasoconstrictor, inhibition of other vasodilator mediators, compared with low-altitude pregnancy. Zamudio suggested that the impact of hypoxia on several vasoactive mediators during pregnancy shifts the general population risk towards the development of preeclampsia (36).

The aim of the present study was to investigate the changes in some vasoactive agents associated with the preeclamptic syndrome at low altitude and determine whether residence at high altitude augments or aggravates the change in these factors.

\section{Materials and Methods}

\section{Study design}

This study followed the instructions in accordance with the ethical standards of the responsible committee on human experimentation and was adherent to the Helsinki Declaration of 1975, revised in 2000 (available at http://www.wma.net/e/policy/17-c_e.html). The study was proved by the Ethical Committee of the College of Medicine, King Khalid University, Saudi Arabia.

\section{Study subjects}

The study was carried out in Aseer region in Southern of Saudi Arabia. Abha city was selected as high altitude (altitude $2700 \mathrm{~m}$ ), while Muhayl city was selected as low altitude (altitude $500 \mathrm{~m}$ ). Eighty (selected randomly) pregnant women (Para 2 to 4) (the ages ranged between 30-39 years) were included in this study who attended to the outpatient clinic in obstetrics and gynecology department in both Abha General Hospital and Muhayl General Hospital. An informed consent was obtained from each subject included in the study. Laboratory samples were collected at the time of diagnosis of preeclampsia (week 28-32) before any medication was prescribed.

The blood pressure in the normotensive group ranged between $110 / 70-120 / 80 \mathrm{mmHg}$ and in the hypertensive group ranged between 160/90 - 175/105 $\mathrm{mmHg}$ (three separate readings were taken at least six hours apart). Diagnosis of proteinuria was confirmed by the presence of 0.3 grams or more protein in a 24-hour urine sample in preeclamptic patients. The subjects were divided into 2 main groups, the first main group was pregnant women who attended Abha General Hospital (40 pregnant women) which included two subgroups: 
(a) Healthy pregnant control (20) and (b) preeclamptic pregnant patients (20). The second main group who attended Muhayl General Hospital (40) included two subgroups: (a) Healthy pregnant control (20) and (b) preeclamptic pregnant women (20). All participants were subjected to history taking and clinical examination. Exclusion criteria among the participants included any serious medical problems such as diabetes or renal or liver affection. Abdominal ultrasound was done for all the participants to assess the liver, the portal vein diameter, the spleen size and the presence or absence of ascites, renal disorders or any other abnormalities. Obstetric ultra-sonography was done by a specialist to exclude any obstetric abnormalities and multiple pregnancies. Three readings for the blood pressure were taken using the ordinary sphygmomanometer technique and urinary proteinuria was measured using commercial kits for detection of the proteinuria.

\section{Blood sampling}

Three venous blood samples were obtained from participants in three visits over one week interval ( $1 \mathrm{ml} / \mathrm{sample})$. Samples were divided into two parts; the first parts were allowed to clot for $20 \mathrm{~min}$, and centrifuged at 14,000 rpm for $10 \mathrm{~min}$. Serum was separated and used for determination of creatinine, serum urea, ET-1 and TNF $\alpha$ levels. The other parts of the blood were added to ethylene diamine tetra-acetic acid (EDTA) and centrifuged at 1,000 rpm for 15 min. Plasma was separated and stored at $-80{ }^{\circ} \mathrm{C}$ for assay of the total plasma nitrite/nitrate $(\mathrm{NOx}), \mathrm{PGI}_{2}$ and $\mathrm{TXA}_{2}$ levels. The mean of three readings was taken for each subject.

\section{Determination of serum urea and creatinine levels}

Serum urea level was determined by the enzymatic colorimetric method using a specialized kit. The method is based on urease (urea amidohydrolase) / glutamate dehydrogenase coupled reactions and uses a two-point fixed time, kinetic scheme for monitoring the rate of consumption of NADH at $340 \mathrm{~nm}$ (7). Serum creatinine level was determined by the Jaffe reaction, where creatinine reacts with picrate ion in an alkaline medium to yield an orange red complex, which was measured at $490 \mathrm{~nm}$ (29).

\section{Determination of serum ET-1, plasma $P G I_{2}$ and $T X A_{2}$ levels}

Serum level of ET-1 was determined using a commercially available sandwich ELISA kit following the instructions of the manufacturer (USCN Life and Technology). The measurable range of ET-1 was 15.6 to $1,000 \mathrm{pg} / \mathrm{ml}$. The intra-assay and inter-assay coefficients of variation were 5.6 and $11 \%$, respectively. Plasma levels of $\mathrm{PGI}_{2}$ and $\mathrm{TXA}_{2}$ were measured by their stable metabolites of 6-keto-PGF $1 \alpha$ and TXB2 by enzyme-linked immunosorbent assay (ELISA). Both 6-keto-PGF1 $\alpha$ and TXB2 ELISA kits were purchased from Oxford Biomedical Research, Ins. (Oxford, MI, USA). Plasma samples for measurements of 6-keto-PGF1 $\alpha$ and $\mathrm{TXB}_{2}$ were extracted by C18 Sep-Pak column (Waters Corporation, Milford, MA, USA) following the standard manufacture instruction before assay.

\section{Determination of plasma NOx, serum tumor necrosis factor-alpha (TNF $\alpha$ ) levels}

The method for the estimation of the plasma NOx level, the metabolites of vasodilator nitrous oxide, was based on the Griess reaction. Plasma nitrite/nitrate levels were measured after the enzymatic conversion of nitrate to nitrite by nitrate reductase in the presence of NADPH. The oxidation of the coenzyme was monitored by the decrease in absorbance at $540 \mathrm{~nm}$. The results were expressed as micromole per liter (16). Serum TNF- $\alpha$ level was determined by cytotoxicity on L929 cells using recombinant TNF- $\alpha$ (BASF/Knoll, Ludwigshafen, Germany; specific activity, $107 \mathrm{U} / \mathrm{mg}$ ) and expressed in picogram per milliliter (5) 
Statistical analysis

The data was expressed as means $\pm \mathrm{SD}$. The Kolmogorov-Smirnov test was used to ensure the normality of the distribution of the data. Testing significance was performed using $\chi^{2}$ test and the one-way analysis of variance (ANOVA). The post hoc Scheffe's test was applied to identify the source of statistical significance. $P$ values less than 0.05 were considered statistically significant.

\section{Results}

\section{Determination of blood pressure}

The blood pressures in preeclamptic patients of both low and high altitude showed significant elevation of systolic (171.45 $\pm 19.76,182.05 \pm 18.94$, respectively) and diastolic blood pressures $(118.95 \pm 12.26,127.20 \pm 12.47$, respectively) compared with the normal pregnant women for systolic $(117.05 \pm 12.17,111.30 \pm 13.62$, respectively) and diastolic blood pressures $(72.55 \pm 7.43,72.10 \pm 9.87$ respectively). There were not any significant changes in both SBP and DBP in preeclamptic patients in high altitude compared with low altitude patients (Table I).

Table I. Showed mean \pm SD for the age, parity, gestational age (GA), body mass index (BMI), systolic blood pressure (SBP), diastolic blood pressure (DBP), serum urea and creatinine levels in different study group

\begin{tabular}{|l|c|c|c|c|}
\hline & NL & NH & PL & PH \\
\hline Age (years) & $33.9 \pm 7.3$ & $32.7 \pm 8.2$ & $35.8 \pm 6.4$ & $34.5 \pm 9.7$ \\
\hline Parity & $4.1 \pm 3.8$ & $3.2 \pm 3.1$ & $3.7 \pm 2.6$ & $3.1 \pm 2.1$ \\
\hline GA (weeks) & $35.6 \pm 4.4$ & $34.9 \pm 3.3$ & $35.7 \pm 3.3$ & $31.7 \pm 8.7$ \\
\hline BMI & $32.1 \pm 3.6$ & $32.6 \pm 5.6$ & $30.8 \pm 4.2$ & $33.6 \pm 4.5$ \\
\hline SBP (mmHg) & $117.05 \pm 12.17$ & $111.30 \pm 13.62$ & $171.45 \pm 19.76^{* \#}$ & $182.05 \pm 18.94^{* \#}$ \\
\hline DBP (mmHg) & $72.55 \pm 7.43$ & $72.10 \pm 9.87$ & $118.95 \pm 12.26^{* \#}$ & $127.20 \pm 12.47^{* \#}$ \\
\hline Serum urea (mg/dl) & $27.59 \pm 3.47$ & $27.56 \pm 3.12$ & $30.67 \pm 4.13$ & $31.29 \pm 3.92$ \\
\hline Serum creatinine (mg/dl) & $0.36 \pm 0.06$ & $0.84 \pm 0.09^{*}$ & $0.72 \pm 0.08^{*}$ & $0.86 \pm 0.09^{*}$ \\
\hline
\end{tabular}

NL normal pregnancy at low altitude group, NH normal pregnancy at high altitude group, PL preeclampsia at low altitude group, $\mathrm{PH}$ preeclampsia at high altitude group. Results are expressed as mean $\pm \mathrm{SD}(n=20)$.

Significance level is at $p<0.05$. * Significantly different from NL group. \# Significantly different from NH group. \pm Significantly different from PL group

\section{Determination of urine proteinuria, serum urea and creatinine levels}

Urine proteinuria was significantly positive (more than $0.3 \mathrm{gm}$ protein $/ 24 \mathrm{~h}$ ) in preeclamptic groups of both high and low altitude while the normal pregnant women of both groups showed absent proteinuria. Serum urea was insignificantly changed in all study groups (27.59 $\pm 3.47,27.56 \pm 3.12,30.69 \pm 4.14,31.295 \pm 3.9$, respectively). Serum creatinine was significantly increased in preeclamptic low altitude patients and high altitude normal and preeclamptic pregnant women $(0.84 \pm 0.09,0.72 \pm 0.08,0.86 \pm 0.09$ respectively) compared with normal pregnant low altitude women $(0.36 \pm 0.06)$, while there was no significant change comparing the three different groups. In spite of these significant changes in serum creatinine, its levels were preserved within the normal values for human indicated no renal insult was present in any of the study groups (Table I). 
Measurement of the systolic and diastolic blood pressure and urinary proteinuria confirmed the diagnosis of preeclampsia in PL and PH groups of pregnant patients. Determination of both serum urea and creatinine excluded other renal causes of proteinuria than the preeclampsia.

\section{Determination of serum ET-1, plasma $P G I_{2}$ and $T X A_{2}$ levels}

Serum ET-1 and plasma TXA $_{2}$ levels in normal pregnant women at high altitude showed a significant elevation $(66.81 \pm 7.36 \mathrm{pg} / \mathrm{ml}, 122.86 \pm 13.37 \mathrm{pg} / \mathrm{ml}$, respectively) compared with the normal pregnant women at low altitude $(48.92 \pm 4.58 \mathrm{pg} / \mathrm{ml}, 89.03 \pm 10.67 \mathrm{pg} / \mathrm{ml})$. Preeclampsia in low altitude produced significant increases in both serum ET-1 and plasma $\mathrm{TXA}_{2}$ levels $(88.39 \pm 9.54 \mathrm{pg} / \mathrm{ml}, 162.73 \pm 15.92 \mathrm{pg} / \mathrm{ml}$, respectively) compared with both the NL and NH groups. The preeclamptic women at high altitude showed a significant elevation of their serum ET-1 and plasma TXA 2 levels $(117.75 \pm 12.96 \mathrm{pg} / \mathrm{ml}, 211.01 \pm 22.69$ $\mathrm{pg} / \mathrm{ml}$, respectively) compared with NL, NH and PL groups (Fig. 1A, B). Normal pregnancy at high altitude significantly decreased the plasma level of $\mathrm{PGI}_{2}(191.57 \pm 19.68 \mathrm{pg} / \mathrm{ml})$ compared with the normal low altitude pregnant women $(238.01 \pm 24.55 \mathrm{pg} / \mathrm{ml})$. On the other hand, preeclampsia at low altitude resulted in a significant reduction of the plasma level of $\mathrm{PGI}_{2}(149.155 \pm 15.66 \mathrm{pg} / \mathrm{ml})$ compared with both NL and NH groups. Preeclampsia at high altitude resulted in a significant reduction of the plasma level of $\mathrm{PGI}_{2}(111.92 \pm 10.74 \mathrm{pg} / \mathrm{ml})$ compared with NL, NH and LP groups of pregnant women (Fig. 1C).
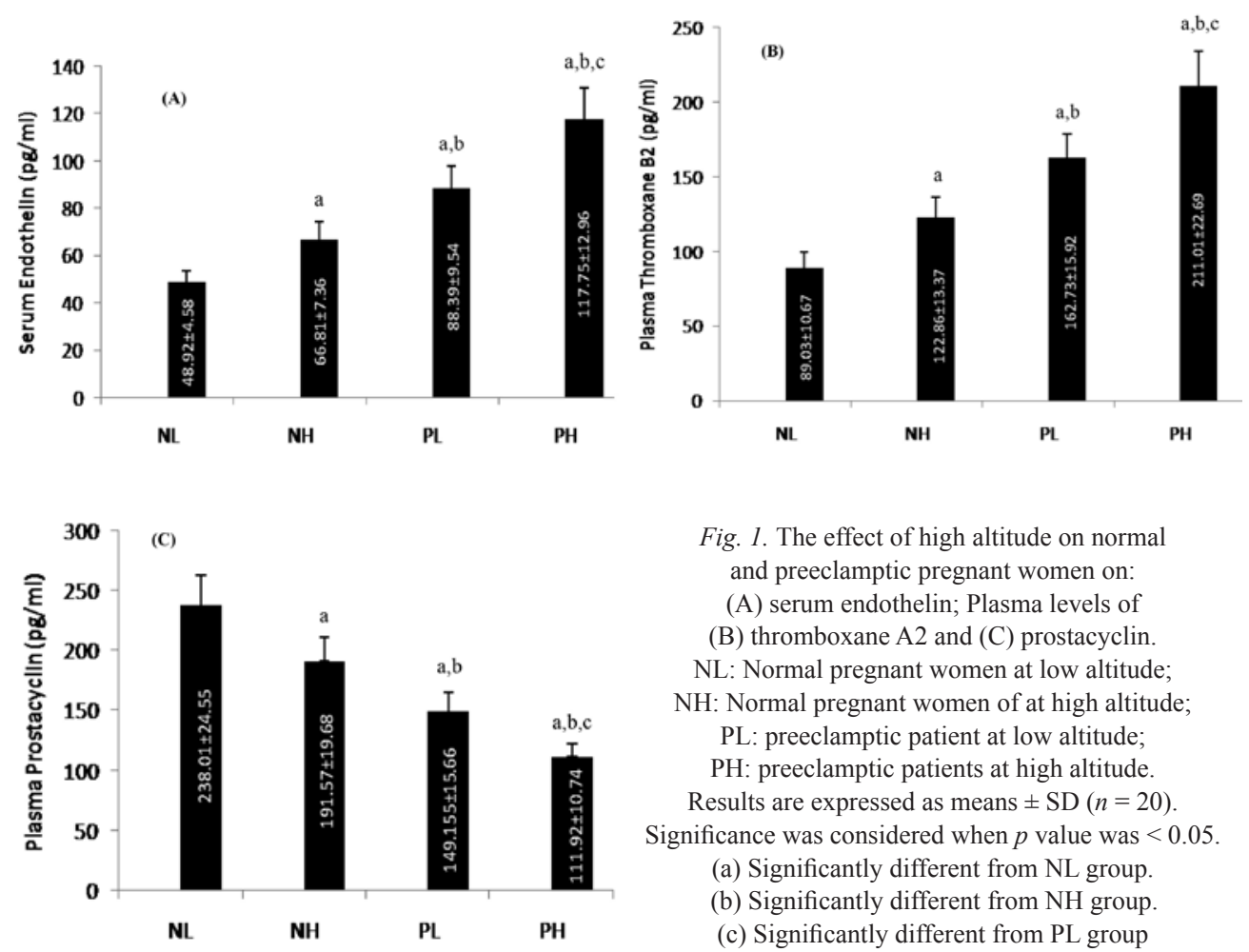

Fig. 1. The effect of high altitude on normal and preeclamptic pregnant women on: (A) serum endothelin; Plasma levels of (B) thromboxane A2 and (C) prostacyclin.

NL: Normal pregnant women at low altitude; NH: Normal pregnant women of at high altitude; PL: preeclamptic patient at low altitude; $\mathrm{PH}$ : preeclamptic patients at high altitude.

Results are expressed as means $\pm \mathrm{SD}(n=20)$. Significance was considered when $p$ value was $<0.05$.

(a) Significantly different from NL group.

(b) Significantly different from NH group.

(c) Significantly different from PL group 
Determination of serum TNF- $\alpha$ and plasma NOx levels

Both TNF- $\alpha$ and plasma NOx levels increased significantly in normal pregnant women at high altitude $(102.23 \pm 13.31 \mathrm{pg} / \mathrm{ml}, 55.53 \pm 6.39 \mu \mathrm{mol} / \mathrm{L}$, respectively) compared with the low altitude normal pregnant group $(69.86 \pm 7.97 \mathrm{pg} / \mathrm{ml}, 34.24 \pm 4.89 \mu \mathrm{mol} / \mathrm{L}$, respectively). While preeclampsia at low altitude significantly increased the serum TNF- $\alpha(142.39 \pm 15.37$ $\mathrm{pg} / \mathrm{ml})$ without any significant changes in NOx plasma levels $(58.94 \pm 7.92 \mu \mathrm{mol} / \mathrm{L})$ compared with the NH group. Preeclampsia at high altitude significantly increased both TNF- $\alpha$ and plasma NOx levels $(196.86 \pm 17.64 \mathrm{pg} / \mathrm{ml}, 97.07 \pm 8.59 \mu \mathrm{mol} / \mathrm{L}$, respectively) compared with the NL, NH and PL groups (Fig. 2A, B).
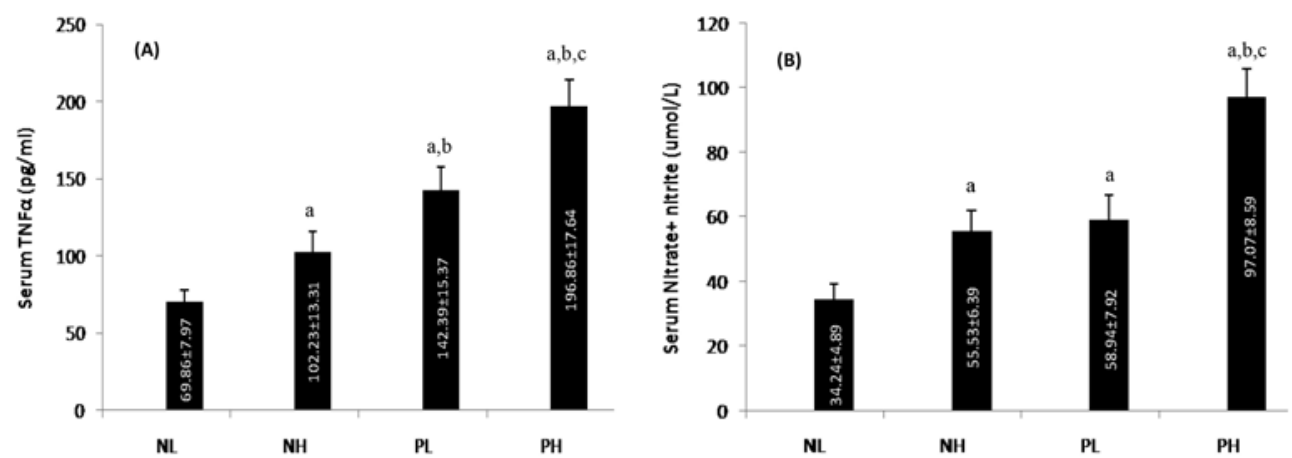

Fig. 2. The effect of high altitude on normal and preeclamptic pregnant women on:

(A) serum levels of TNF- $\alpha$ and (B) nitrite/nitrate ratio. NL: Normal pregnant women at low altitude;

NH: Normal pregnant women of at high altitude; PL: preeclamptic patient at low altitude;

PH: preeclamptic patients at high altitude. Results are expressed as means $\pm \operatorname{SD}(n=20)$. Significance was considered when $p$ value was $<0.05$. (a) Significantly different from NL group. (b) Significantly different from NH group. (c) Significantly different from PL group

\section{Discussion}

Increased incidence of preeclampsia at high altitude is a well-documented phenomenon $(1,20,36)$. The present study focused on the mechanisms by which high altitude increases maternal risk for the development of preeclampsia through the disturbance in the vasoactive mediators. Our results suggests that residence at high altitude enhances vasoconstrictor relative to vasodilator mediators and endothelial inflammatory processes in normal pregnancy, and more so during preeclampsia as compared to the corresponding states at low altitude.

Although various researches concerning the cause and mechanism of preeclampsia have taken place, its exact pathogenesis remains uncertain. Increased vasoconstriction and exaggerated inflammatory response are important contributors to the pathophysiology of preeclampsia (32). Several studies support the notion that in preeclampsia, endothelial dysfunction involves generalized damage to the maternal endothelium, associated with the release of vasoconstrictors, up-regulation inflammatory mediators and imbalance between $\mathrm{PGI}_{2}$ and $\mathrm{TXA}_{2}$ (13).

To our knowledge, this is the first study to investigate the changes in $\mathrm{TXA}_{2}$ and $\mathrm{PGI}_{2}$ in preeclampsia at high altitude. Our results showed that preeclampsia at low altitude, as expected, was associated with increased $\mathrm{TXA}_{2}$ and decreased $\mathrm{PGI}_{2}$ compared to low altitude 
normal pregnancy. Normal pregnancy at high altitude caused similar but less pronounced changes of these factors. However, preeclampsia at high altitude resulted in marked augmentation of these vasoactive markers changes (Fig. 1B, C). Lewis et al. suggest that during preeclampsia, decreased plasma $\mathrm{PGI}_{2}$ level with increased plasma $\mathrm{TXA}_{2}$ level and the imbalance between $\mathrm{PGI}_{2}$ and $\mathrm{TXA}_{2}$ contributes significantly to the increased vasoconstriction in both the maternal systemic and the placental vasculatures (22). Normal maternal physiology at high altitude could be considered to resemble an intermediate state between preeclampsia and normal pregnancy of low altitude (23). Our results suggest that this imbalance is even more severe in preeclampsia at high altitude and thus may be a major contributor to the altitude associated higher risk of preeclampsia.

In the current study, ET-1 levels increased significantly in preeclamptic versus normal pregnant women at low altitude. The combination of high altitude and preeclampsia produced a further significant increase in ET-1 levels (Fig. 1A). This is in agreement with the study of Angerio who reported that hypoxia at high altitude induced ET-1 release (1). Several lines of evidence suggested a role for ET-1, as potent endothelial derived vasoconstrictor, in the pathophysiology of preeclampsia (13). A previous study suggested that ET-1 plays an essential role in the failure of trophoblast invasion in the early stages of preeclampsia (12). Another study indicated that the level of circulating ET-1 correlates with the severity of the disease symptoms (4). Coincidental with the increase in circulating ET-1, Nishikawa et al. reported a significant negative correlation between ET-1 levels and levels of the vasodilators NO and cGMP in preeclamptic women (24). We observed an increase in serum nitrite/nitrate in preeclamptic patients at low altitude and in both normal and preeclamptic pregnancies at high altitude (Fig. 2B). This possibly reflects the increased nitric oxide catabolic rate by the high oxidative stress level in preeclampsia augmented by high altitude (27). It has been reported that under conditions of severe oxidative stress, NO is consumed by superoxide, to form highly reactive oxidant species, causing disturbances in the vascular endothelium with impairment of its function (30). We suggest that the increased oxidative stress induced by the high altitude hypoxia results in hypersecretion of ET-1 with subsequent aggravation of the preeclamptic pathophysiological process.

Our study showed elevated TNF- $\alpha$ serum level in preeclamptic high altitude residence women compared with lower residence preeclamptic, and normal non-preeclamptic pregnant women at both low and high altitude (Fig. 2A). Exaggerated inflammatory responses were believed to be a significant pathophysiological event during preeclampsia (25). Several biochemical parameters indicate that endothelial dysfunction is related to the inflammatory response in preeclampsia, such as elevated serum cellular fibronectin, endothelial adhesion molecules P-selectin, the intercellular adhesion molecule, the vascular cell adhesion molecule, and the platelet endothelial cell adhesion molecule levels $(2,19,21,31,33)$. A previous study reported that the pro-inflammatory cytokines increased significantly in preeclamptic women compared to women with normal pregnancies at sea level (28). The overall profile of cytokine production during pregnancy at high altitude is increased by sympatho-adrenal activation secondary to the interaction of hypoxia and pregnancy (11). It was reported that maternal circulating concentrations of the pro-inflammatory cytokines TNF- $\alpha$, IL- 6 , and IL- 8 were elevated late in normal pregnancy in women residing at high altitude compared to nonpregnant women (9). The interaction between the inflammatory cytokines and the vasoactive mediators has been investigated. Marks et al. have reported that the elevation of proinflammatory cytokine TNF- $\alpha$ induces ET-1 expression and has been linked to an increase in 
circulating concentrations of endothelial cell adhesion molecules in preeclampsia especially at high altitude (23). Therefore, combining the effect of high altitude to that of preeclampsia can be expected to produce a marked elevation in these inflammatory cytokines.

Our study demonstrates that residence at high altitude is associated with enhanced production of $\mathrm{TXA}_{2}$, decreased $\mathrm{PGI}_{2}$ as well as increased levels of ET-1 and TNF- $\alpha$ during normal pregnancy, and more so during preeclampsia. Further research is needed to identify which of the markers of vascular dysfunction will be useful in early detection and follow up of preeclamptic women at high altitude. The result suggests that the management of preeclampsia at high altitude may require movement to a lower altitude. However, we would like to extend our studies to investigate whether the suggested therapeutic approaches like low dose aspirin, to readjust the balance in favor of production of more $\mathrm{PGI}_{2}$ relative to $\mathrm{TXA}_{2}$ (8), or ET-1 receptor antagonists (14), would also work at high altitude.

\section{Acknowledgements}

This research was fully funded by a grant from the deanship of scientific research, King Khalid University, KSA, Project No. 280-2013G-1433H. The authors highly appreciate the extreme help of all staff members of Abha General Hospital and Muhayl General Hospital, especially the general managers Dr. Maeet Abd Alla Aseery, Nursing staff, technicians and Dr. Khalid S Bashir for their help in collection and processing of samples and data. We extend our thanks to all staff members and technicians of the Physiology and Biochemistry Departments of Colleges of Medicine, King Khalid University, Saudi Arabia, and College of Medicine, Menoufiya University, Egypt; for their great help in every step in this work.

\section{REFERENCES}

1. Angerio AD: Endothelin-mediated preeclampsia at high altitude. Crit. Care Nurs. Q. 23, 73-78 (2000)

2. Austgulen R, Lien E, Vince G, Redman CWG: Increased maternal plasma levels of soluble adhesion molecules (ICAM-1, VCAM-1, E-selectin) in preeclampsia. Eur. J. Obstet. Gynec. Reprod. Biol. 7, 53-58 (1997)

3. Bailey DM, Dehnert C, Luks AM, Menold E, Castell C, Schendler G, Faoro V, Gutowski M, Evans KA, Taudorf S, James PE, McEneny J, Young IS, Swenson ER, Mairbäurl H, Bärtsch P, Berger MM: High-altitude pulmonary hypertension is associated with a free radical-mediated reduction in pulmonary nitric oxide bioavailability. J. Physiol. 588, 4837-4847 (2010)

4. Baksu B, Davas I, Baksu A, Akyol A, Gulbaba G: Plasma nitric oxide, endothelin-1 and urinary nitric oxide and cyclic guanosine monophosphate levels in hypertensive pregnant women. Int. J. Gynaecol. Obstet. 90, 112-117 (2005)

5. Barber E, Menendez S, León OS, Barber MO, Merino N, Calunga JL, Cruz E, Bocci V: Prevention of renal injury after induction of ozone tolerance in rats submitted to warm ischemia. Mediat. Inflamm. 8, 37-41 (1999)

6. Baumwell S, Karumanchi SA: Pre-eclampsia: Clinical manifestations and molecular mechanisms. Nephron Clin. Pract. 106, c72-c81 (2007)

7. Bretaudiere JP, Phung HT, Baily M: Direct enzymatic determination of urea in the plasma and urine with a centrifugal analyzer. Clin. Chem. 22, 1614-1617 (1976)

8. Bujold E, Roberge S, Lacasse Y, Bureau M, Audibert F, Marcoux S, Forest JC, Giguère Y: Prevention of preeclampsia and intrauterine growth restriction with aspirin started in early pregnancy: a meta-analysis. Obstet. Gynecol. 116, 402-414 (2010)

9. Coussons-Read ME, Mazzeo RS, Whitford MH, Schmitt M, Moore LG, Zamudio S: High altitude residence during pregnancy alters cytokine and catecholamine levels. Am. J. Reprod. Immunol. 48, 344-354 (2002)

10. Duley L: The global impact of pre-eclampsia and eclampsia. Semin. Perinatol. 33, 130-137 (2009)

11. Duplain H, Vollenweider L, Delabays A, Nicod P, Bartsch P, Scherrer U: Augmented sympathetic activation during short-term hypoxia and high-altitude exposure in subjects susceptible to high-altitude pulmonary edema. Circulation 99, 1713-1718 (1999) 
12. Fiore G, Florio P, Micheli L, Nencini C, Rossi M, Cerretani D, Ambrosini G, Giorgi G, Petraglia F: Endothelin-1 triggers placental oxidative stress pathways: putative role in preeclampsia. J. Clin. Endocrinol. Metab. 90, 4205-4210 (2005)

13. George EM, Granger JP: Endothelin: Key mediator of hypertension in preeclampsia. Am. J. Hypertens. 24, 964-969 (2011)

14. George EM, Granger JP: Linking placental ischemia and hypertension in preeclampsia: role of endothelin 1. Hypertension 60, 507-511 (2012)

15. Gilbert JS, Ryan MJ, LaMarca BB, Sedeek M, Murphy SR, Granger JP: Pathophysiology of hypertension during preeclampsia: linking placental ischemia with endothelial dysfunction. Am. J. Physiol. Heart Circ. Physiol. 294, H541-H550 (2008)

16. Green LC, Tannenbaum SR, Goldman P: Nitrate synthesis in the germ free and conventional rat. Science 212, 56-58 (1981)

17. Hale SA, Weger L, Mandala M, Osol G: Reduced NO signaling during pregnancy attenuates outward uterine artery remodeling by altering MMP expression and collagen and elastin deposition. Am. J. Physiol. Heart Circ. Physiol. 301, H1266-H1275 (2011)

18. Julian CG, Galan HL, Wilson MJ, Desilva W, Cioffi-Ragan D, Schwartz J, Moore LG: Lower uterine artery blood flow and higher endothelin relative to nitric oxide metabolite levels are associated with reductions in birth weight at high altitude. Am. J. Physiol. Regul. Integr. Comp. Physiol. 295, R906-R915 (2008)

19. Krauss T, Kuhn W, Lakoma C, Augustin HG: Circulating endothelial cell adhesion molecules as diagnostic markers for the early identification of pregnant women at risk for development of preeclampsia. Am. J. Obstet. Gynecol. 177, 443-449 (1997)

20. Kumtepe Y, Dündar O, Cetinkaya K, Ingeç M: Preeclampsia and eclampsia incidence in the eastern anatolian region of Turkey: the effects of high altitude. J. Turk. Ger. Gynecol. Assoc. 12, 26-30 (2011)

21. LaMarca B, Speed J, Fournier L, Babcock SA, Berry H, Cockrell K, Granger JP: Hypertension in response to chronic reductions in uterine perfusion in pregnant rats: effect of tumor necrosis factor-alpha blockade. Hypertension 52, 1161-1167 (2008)

22. Lewis D, Canzoneri BJ, Gu Y, Zhao S, Wang Y: Maternal levels of prostacyclin, thromboxane, ICAM, and VCAM in normal and preeclamptic pregnancies. Am. J. Reprod. Immunol. 64, 376-383 (2010)

23. Marks L, Zamudio S, Cousins F, Duffie F, Lyall L: Endothelial activation and cell adhesion molecule concentrations in pregnant women living at high altitude. J. Soc. Gynecol. Invest. 13, 399-403 (2006)

24. Nishikawa S, Miyamoto A, Yamamoto H, Ohshika H, Kudo R: The relationship between serum nitrate and endothelin-1 concentrations in preeclampsia. Life Sci. 67, 1447-1454 (2000)

25. Redman CWG, Sacks GP, Sargent IL: Preeclampsia: An excessive maternal inflammatory response to pregnancy. Am. J. Obstet. Gynecol. 180, 499-506 (1999)

26. Roberts JM, Pearson G, Cutler J, Lindheimer M: Summary of the NHLBI working group on research on hypertension during pregnancy. Hypertension 41, 437-445 (2003)

27. Rostami M, Jorfi M: Evaluation of serum nitrite nitrate and malondialdehyde concentrations in preeclampsia. J. Reprod. Infertil. 11, 105-112 (2010)

28. Saito S, Umekage H, Sakamoto Y, Sakai M, Tanebe K, Sasaki Y, Morikawa H: Increased T-helper-1-type immunity and decreased T-helper-2-type immunity in patients with preeclampsia. Am. J. Reprod. Immunol. 41, 297-306 (1999)

29. Spencer K: Analytical reviews in clinical biochemistry: the estimation of creatinine. Ann. Clin. Biochem. 23, $1-25$ (1986)

30. Steiner DRS, Gonzalez NC, Wood JG: Interaction between reactive oxygen species and nitric oxide in the microvasculature response to systemic hypoxia. J. Appl. Physiol. 93, 1411-1418 (2002)

31. Taylor RN, Crombleholme WR, Friedman SA, Jones LA, Casal DC, Roberts JM: High plasma cellular fibronectin levels correlate with biochemical and clinical features of preeclampsia but cannot be attributed to hypertension alone. Am. J. Obstet. Gynecol. 165, 895-901 (1991)

32. Vitoratos N, Hassiakos D, Iavazzo C: Molecular mechanisms of preeclampsia. J. Pregnancy 2012, 298343 (2012)

33. Wang Y, Lewis DF, Groome L, Zhang Y, Gu Y, Philibert L: Enhanced P-selectin expression in the maternal vessel endothelium and elevated soluble P-selectin levels in the maternal plasma in women with preeclampsia. J. Soc. Gynecol. Investig. 12, 276A (2005)

34. Xiao D, Hu XQ, Huang X, Zhou J, Wilson SM, Yang S, Zhang L: Chronic hypoxia during gestation enhances uterine arterial myogenic tone via heightened oxidative stress. PLoS One 8, e73731 (2013)

35. Xu B, Nakhla S, Makris A, Hennessy A: TNF- $\alpha$ inhibits trophoblast integration into endothelial cellular networks. Placenta 32, 241-246 (2011)

36. Zamudio S: High-altitude hypoxia and preeclampsia. Front. Biosci. 12, 2967-2977 (2007) 